\title{
Meningkatkan Kreativitas Anak Usia 5-6 Tahun melalui Media Magic Puffer Ball
}

\author{
Balandina Debeturu ${ }^{1}$, Lanny Wijayaningsih \\ Program Studi PG-PAUD, FKIP, Universitas Kristen Satya Wacana
}

\begin{abstract}
This study aims to improve the creativity of children in TK Marsudirini Sang TimurSalatiga group B2.This study uses classroom action research (PTK).Research subjects in TKMarsudirini Sang TimurSalatiga B2 groups numbered 20 children, 9 boys and 11 girls. The technique of collecting data through observation and documentation. The results showed an increase in children's creativity through the use of "magic puffer ball" media, namely creativity in the pre-cycle of $22 \%$ of 20 children, increased creativity in the first cycle of the first meeting of $38 \%$ from 20 children, the second cycle of the meeting was $44 \%$ and increased creativity in Cycle II, the first meeting was $61 \%$ of 20 children, the second cycle of the second meeting was $75 \%$. The indicators used are able to enrich and develop an idea or product and add or detail the details of an object, idea or situation so that it is more interesting. The conclusion of this study is that the use of "magic puffer ball" media can improve children's creativity.
\end{abstract}

Keywords: creativity; media, magic puffer ball

\begin{abstract}
Abstrak
Penelitian ini bertujuan untuk meningkatkan kreativitas anak di TKMarsudirini Sang Timur Salatigakelompok B2. Penelitian ini menggunakan penelitian tindakan kelas (PTK). Subjek penelitian di TK Marsudirini Sang Timur Salatiga kelompok B2 berjumlah 20 anak, 9 lakilaki dan 11 perempuan. Teknik pengumpulan data melalui observasi dan dokumentasi. Hasil penelitian menunjukan adanya peningkatan kreativitas anak melalui penggunan media "magic puffer ball", yaitu kreativitas pada pra siklus sebesar 22\% dari 20 anak, peningkatan kreativitas pada siklus I pertemuan pertama sebesar 38\% dai 20 anak, siklus I pertemuan ke dua sebesar $44 \%$ dan peningkatan kreativitas disiklus II pertemuan pertama sebesar $61 \%$ dari 20 anak, siklus II pertemuan kedua sebesar 75\%. Adapun indikator yang digunakan yaitu mampu memperkaya dan mengembangkan suatu gagasan atau produk dan menambahkan atau memperinci detil-detil dari suatu objek, gagasan atau situasi sehingga lebih menarik. Kesimpulan dari penelitian ini adalah penggunaan media "magic puffer ball" dapat meningkatkan kreativitas anak.
\end{abstract}

Kata Kunci: Kreativitas; Media; Magic Puffer Ball

@ Jurnal Obsesi Prodi PG-PAUD FIP UPTT 2019

$\triangle$ Corresponding author :

Address : Diponegoro 52-60, Jawa Tengah, Indonesia

ISSN 2356-1327 (Media Cetak)

Email : 272015008@student.uksw.edu

ISSN 2549-8959 (Media Online) 


\section{PENDAHULUAN}

Menurut John W. Haefele kreativitas meupakan kemampuan untuk membuat sesuatu yang baru dan bernilai social (Munfarijah, 2018). Suroso kreativitas merupakan kebutuhan pada masa kini dan masa yang akan datang. Kreativitas diperlukan agar dapat menjemput abad persaigan pengembangan kreativitas seseorang yang menghasilkan karya inovatif atau sesuatu yang baru dan dibutuhkan pada zaman sekarang (Husna Handayani, 2018). Menurut Santrock keativitas ialah suatu kemampuan dalam berfikir mengenai sesuatu dengan mengunakan cara yang tidak biasa dalam menyelesaikan masalah(Yosep, 2014). Menurut Sujiono kreativitas ialah kemampuan saat mimikirkan, menciptakan, mengadakan dan menemukan suatu bentuk ataupun gagasan baru yang origilan yang bisa berguna bagi orang itu sendiri dan orang lain (Ardiyanto, 2017)

Setyabudi kreativitas merupakan proses penyatuan perngetahuan dari berbagai macam bidang pengalaman yang berlainan dalam menghasilkan ide-ide yang bermanfaat dengan menggunakan cara baru dengan lebih baik serta mampu merealisasikannya (Istiqomah, 2017). Suluso menyatahkan bahwa kreativitas ialah aspek kognitif yang mendatangkan hasil dengan cara pandagan baru terhadap suatu masalah atau situasi (Djuniartiningsih, 2012). Kreativitas merupakan kemampuan menciptakan produk baru baik yang benar-benar baru maupun memodifikasi apa yang sudah ada menjadi baru. (Fauziddin, 2016). Menurut NACCCE (National Advisory Committee on Creative and Cultural Education) menyatahkan bahwa keativitas ialah suatu aktivitas yang dilakukan dengan imajinasi dan menghasilkan hal bau dan benilai (Nirwana, Widyaningsih, \& Sapaile, 2019).
Berdasarkan pernyatan para ahli diatas, maka peneliti menarik kesimpulan bahwa kreativitas merupakan suatu kemampuan yang dimiliki oleh seseorang dalam menciptakan suatu karya yang didapatkan dari berbagai macam ide, gagasan, dan imajinasi orang itu sendiri. Adanya kreativitas, orang-orang bisa melakukan kegiatan yang dapat menghibur diri sendiri dan juga menghasilkan karya yang diinginkan.

Menurut Wallas ada empat tahap dalam proses kreatif yaitu: persiapan, inkubasi, iluminasi, dan verifikasi (Priyanto, 2014). Menurut Rachmawati mengatakan bahwa ada beberapa strategi yang dapat mengembangkan kreativitas anak yaitu: 1) pengembangan kreativitas dengan menciptakan produk (hasrat karya), bertujuan untuk mengembangkan kreativitas pada anak dan kognitif anak dalam menciptakan produk dengan mengajak anak membentuk sesuatu secara bebas, 2) mengajak anak untuk bereksplorasi agar dapat mengembangkan kreativitasnya, karena anak bisa belajar secara langsung dari pegalamannya, 3) mengajak anak melakukan kegiatan eksperimen untuk belajar memecahkan suatu masalah, 4) pengembangan kreativitas melalui kegiatan proyek dilakukan secara berkelompok untuk membuat sebuahhasil karya, 5) melibatkan indra pendengar dan alat-alat musik, anak diajak untuk berkreasi dengan musik, 6) pengembangan melalui bahasa adalah kegiatan yang bisa dilakukan dengan cara mendongeng, menceritakan pengalaman yang pernah didengarkan, 7) pengembangan kreativitas melalui imajinasi, karena strategi ini sudah melekat dilakukan dalam diri anak, sehingga kegiatan yang melibatkan imajinasi anak akan membantu anak dalam mengembangkan kreativitas (Sari, Antara, \& Ujianti, 2017) 
Paul Torrance dari Universitas Georgia menyebutkan ada beberapa ciri-ciri tindakan kreatif anak yaitu: (1) anak yang kreatif belajar mengunakan dengan caracara kreatif (2) anak yang kreatif mempunyai perhatian yang panjang tehadap sesuatu hal yang dibutuhkan usaha menjadi kreatif (3) anak kreatif dapat mengorganisasikan terhadap hal yang tidak biasa (4) anak kreatifbanyak belajar malalui imajinasi untuk memecahkan suatu permasalahan dari pengalaman yang pernah dialami (5) anak kreatif dapat bercerita dengan menggunakan kata-kata dan tempat sebagai objeknya (Miranda, 2018).

Menurut Susanto ada empat dimensi (4P) kreativitas yang saling berkesinambungan yaitu: pribadi (person) kreatif dengan melibatkan diri pada proses (process) kreatif, dengan memberikan dukungan dan dorongan (pess) dari lingkungan (Fauziah, 2018).

Kreativitas Anak usia dini dapat ditingkatkan dengan menggunakan berbagai cara seperti mendongeng, menggambar dan bermain dengan menggunakan alat selain itu suasana yang harus diciptakan juga harus menyenangkan bagi anak (Fakhriyani, 2018) Meningkatkan kreativitas anak usia dini dapat menggunakan permainan, karena permainan merupakan salah satu media yang dapat memotivasi anak untuk mengurangi rasa bosan dan jenuh pada saat kegiatan belajar mengajar (Kartini \& Sujarwo, 2017)

Gagne menyatakan bahwa media adalah berbagai macam komponen yang ada dalam berbagai lingkungan siswa. Yusuf Hadi Miarsono menyatakan bahwa pengertian media dengan segala sesuatu yang dapat digunakan dalam menyalurkan pesan untuk bisa merangsang pikiran, perasaan, perhatian, dan kemauan siswa saat belajar (Mahnun, 2012).
Media yang digunakan dalam penelitian yang peneliti lakukan adalah dengan menggunakan media magic puffer ball. Media ini merupakan suatu permainan edukatif yang baru dan belum terlalu banyak orang yang mengetahui media ini. Media ini akan membantu untuk meningkatkan kreativitas anak. Tekstur dari media ini sangat menarik bagi anak, karena mempunyai bentuk yang unik, bagus, mempunyai beberapa macam warna, mempunyai beberapa aksesoris untuk dihias, juga ringan pada saat dipegang sehingga mempunyai daya tarik untuk dimainkan oleh anak. Penggunaan media yang baru ini membantu agar anak dapat berimajinasi dan menemukan ide yang akan dibuat untuk membentuk sesuatu dari magic puffer ball. Selain ringan lembut pada saat disentuh, media ini juga dapat dibentuk dengan kreasi 3D. Permainan ini adalah permainan bongkar pasang yang dapat digunakan berulang kali oleh anak-anak.

Kelebihan pada media magic puffer ball adalah bahan terbuat dari karet, pada saat menempel tidak harus menggunakan lem, mempunyai bentuk seperti buah rambutan sehingga mudah ditempel satu dengan yang lain, mempunyai beberapa macam warna yang dapat menarik perhatian anak, ringan pada saat dipegang dan dimainkan, memiliki tambahan aksesoris untuk dihias, dapat membuat bentuk 3D, dan dapat membentuk berbagai macam bentuk. Kekurangan dari media magic puffer ball adalah bentuknya yang seperti buah rambutan dan mempunyai banyak rambu-rambu yang mungkin dapat mengganggu rambut anak sehingga tidak baik jika didekatkan pada anak yang memiliki rambut yang panjang.

Dari hasil observasi yang dilakukan dilapangan yaitu di TK B2 Marsudirini Sang Timur Salatiga, masih ada anak-anak yang kreativitasnya belum terlalu diperlihatkan oleh anak-anak dengan baik. 
Didapatkan pada saat pembelajaran yang dilakukan, masih ada anak-anak yang diberikan media seperti plastisin untuk membuat bentuk, masih menurut bentuk yang sama yang dilakukan oleh guru. Hal ini membuktikan kreativitas anak belum berkembang dengan baik. Dari permasalahan di atas, maka peneliti melakukan penelitian untuk membantu anak-anak dalam meningkatkan kreativitas anak-anak melalui penggunaan media magic puffer ball di TK B2 Marsudirini Sang Timur Salatiga.

Media magic puffer ball adalah media/permainan baru yang bentuknya seperti buah rambutan dan media tersebut berukuran kecil-kecil. Media tersebut dapat membuat berbagai macam bentuk sesuai dengan keinginan yang ada pada diri anak itu sendiri. Membuat bentuk dari media magic puffer ball memberikan kesempatan kepada anak untuk berimajinasi, menemukan ide, atau gagasan anak yang akan membuat bentuk agar dapat membantu meningkatkan kreativitas anak-anak. Media ini membantu mengembangkan kreativitas anak dan membantu melatih motorik halus anak karena pada saat membuat membutuhkan koordinasi tangan untuk mebuat bentuk-bentuk dari media magic puffer ball. Peneliti memilih penggunaan media magic puffer ball pada penelitian ini dikarenakan, media tersebut belum pernah digunakan disekolah TK B2 Marsudirini Sang Timur Salatiga. Media ini sangat menarik perhatian anak karena bentuknya yang unik, memiliki beberapa macam warna, dan mudah digunakan oleh anak. Tujuan penelitian ini dilakukan untuk meningkatkan kreativitas anak dengan menggunakan media magic puffer ball di TK Marsudirini Sang Timur Salatiga.

\section{METODOLOGI}

Jenis penelitian ini adalah Penelitian Tindakan Kelas (PTK) yang dilakukan di TK B2 Marsudirini Sang Timur Salatiga. Jumlah anak dalam satu kelas sebanyak 20 anak, dengan kategori 9 anak laki-laki dan 11 anak perempuan. Pengumpulan data dalam penelitian ini menggunakan instrument penelitian observasi dan dokumentasi. Adapun kisi-kisi penilaian ditampilkan pada Tabel 1 .

\section{Tabel 1. Penilaian Kreativitas Anak Melalui} Media Magic Puffer Ball

\begin{tabular}{|c|c|c|}
\hline Fokus & Indikator & Skor \\
\hline \multirow{3}{*}{$\begin{array}{l}\text { Mampu } \\
\text { memperkaya } \\
\text { dan } \\
\text { mengembang } \\
\text { kan suatu } \\
\text { gagasan atau } \\
\text { produk. }\end{array}$} & $\begin{array}{l}\text { Anak dapat membuat } 3 \text { bentuk } \\
\text { dari media yang diberikan. }\end{array}$ & 3 \\
\hline & $\begin{array}{l}\text { Anak dapat membuat } 2 \text { bentuk } \\
\text { dari media yang diberikan. }\end{array}$ & 2 \\
\hline & $\begin{array}{l}\text { Anak dapat membuat } 1 \text { bentuk } \\
\text { dari media yang diberikan. }\end{array}$ & 1 \\
\hline \multirow{3}{*}{$\begin{array}{l}\text { Menambah- } \\
\text { kan atau } \\
\text { memperinci } \\
\text { detil-detil dari } \\
\text { suatu objek, } \\
\text { gagasan atau } \\
\text { situasi } \\
\text { sehingga } \\
\text { lebih } \\
\text { menarik. }\end{array}$} & $\begin{array}{l}\text { Anak dapat menambahkan5-6 } \\
\text { hiasan dengan asesoris dalam } \\
\text { bentuk yang telah dibuat }\end{array}$ & 3 \\
\hline & $\begin{array}{l}\text { Anak dapat menambahkan3-4 } \\
\text { hiasan dengan asesoris dalam } \\
\text { bentuk yang telah dibuat }\end{array}$ & 2 \\
\hline & $\begin{array}{l}\text { Anak dapat menambahkan } 1-2 \\
\text { hiasan dengan asesoris dalam } \\
\text { bentuk yang telah dibuat. }\end{array}$ & 1 \\
\hline
\end{tabular}

Data dianalisa dengan menggunakan statistika deskriptif sederhana dengan rumus sebagai berikut (Yoni dalam Nuraini, 2015):

\section{skorkeseluruhanyangdiperoleh Jumlahskormaksimum}

\section{HASIL DAN PEMBAHASAN}

\section{Prasiklus}

Tindakan awal atau prasiklus yang dilakukan oleh peneliti untuk megumpulkan data kreativitas anak. Hasil penilaian yang dilakukan melalui observasi sesuai dengan indikator penilaian kreativitas anak. Kegiatan prasiklus yang dilakukan anakanak diberikan kesempatan untuk membuat 
bentuk dari media plastisin. Hasil yang didapatkan pada prasiklus dengan presentase $22 \%$. Berikut tabel hasil prasiklus:

Tabel 2. Hasil Presentase Pencapaian Anak dengan Presentase Keberhasilan

\begin{tabular}{|c|c|c|}
\hline \multirow{2}{*}{ No } & \multirow{2}{*}{$\begin{array}{c}\text { Nama } \\
\text { Anak }\end{array}$} & $\begin{array}{c}\text { Pra Tindakan } \\
\text { Presentase } \\
\text { Pencapaian }\end{array}$ \\
\hline 1 & $\mathrm{Ra}$ & $16,6 \%$ \\
\hline 2 & $\mathrm{Ni}$ & $0 \%$ \\
\hline 3 & $\mathrm{Bi}$ & $33,3 \%$ \\
\hline 4 & $\mathrm{Lo}$ & $16,6 \%$ \\
\hline 5 & $\mathrm{Ka}$ & $33,3 \%$ \\
\hline 6 & $\mathrm{Na}$ & $33,3 \%$ \\
\hline 7 & $\mathrm{Ad}$ & $33,3 \%$ \\
\hline 8 & $\mathrm{Ju}$ & $16,6 \%$ \\
\hline 9 & $\mathrm{Di}$ & $16,6 \%$ \\
\hline 10 & $\mathrm{Ra}$ & $33,3 \%$ \\
\hline 11 & $\mathrm{Fe}$ & $33,3 \%$ \\
\hline 12 & $\mathrm{Je}$ & $0 \%$ \\
\hline 13 & $\mathrm{Kal}$ & $16,6 \%$ \\
\hline 14 & $\mathrm{Is}$ & $16,6 \%$ \\
\hline 15 & $\mathrm{Ab}$ & $16,6 \%$ \\
\hline 16 & $\mathrm{Me}$ & $33,3 \%$ \\
\hline 17 & $\mathrm{Ar}$ & $33,3 \%$ \\
\hline 18 & $\mathrm{Fi}$ & $0 \%$ \\
\hline 19 & $\mathrm{Ze}$ & $16,6 \%$ \\
\hline 20 & $\mathrm{Ni}$ & $33,3 \%$ \\
\hline & Rata-rata & $\mathbf{2 2 \%}$ \\
\hline & & \\
\hline
\end{tabular}

\section{Siklus I}

Tahap-tahap dalam penelitian adalah tahap perencanaan, pelaksanaan, evaluasi, dan refleksi. Tahap perencanaan pada tindakan siklus I pertemuan pertama dilakukan dengan membuat rancangan pembelajaran. Penelitian ini membuat sebuah kegiatan yang telah dilakukan sebagai berikut: (1) menyusun rencana program pembelajaran harian (RPPH) yang manjadi panduan bagi peneliti dalam melaksanakan proses belajar mengajar atau pelaksanaan penelitian (2) mempersiapkan media pembelajaran yang digunakan dalam pembelajaran untuk meningkat kreativtas anak menggunakan media magic puffer ball. (3) menyusun lembar observasi mengenai meningkatkan kreativitas anak menggunakan media magic puffer ball yang berisi tentang aspek-aspek penilaian yang meliput mampu memperkaya dan mengembangkan suatu gagasan atau produk, Menambahkan atau memperinci detil-detil dari suatu objek, gagasan atau situasi sehingga lebih menarik. Pertemuan pertama pada siklus I dilakukan pada hari Senin, 15 Oktober 2018. Sebelum melaksanakan kegiatan untuk meningkatkan kreativitas anak, peneliti menyiapkan media yang akan digunakan, untuk mendukung kreativtas anak. Hasil meningkatkan kreativitas anak di TK B2 Marsudirini Sang Timur Salatiga pada Siklus I dilakukan sebanyak dua kali pertemuan diantaranya siklus I pertemuan pertama pada saat membuat bentuk mendapatkan hasil sebesar 35\% dan hasil dari menambahkan assesoris sebesar $40 \%$ hasil keseluruhan yang dihitung dari keduanya yaitu 38\%. Siklus I pertemuan kedua hasil dari membuat bentuk sebesar $38 \%$ dan menambahkan assesoris sebesar $50 \%$ hasil keseluruhan yang dihitung dari keduanya yaitu $44 \%$.

Refleksi dalam penelitian ini adalah evaluasi atau penilaian dalam pembelajaran pada tindakan siklus I. Berdasarkan pengamatan dan analisa pada siklus I ditemukan beberapa masalah yang dihadapi sebagai berikut: (1) meningkatkan kreativitas anak dalam satu kelas belum terlalu terlihat, dikarenakan pada saat membuat bentuk anak-anak masih banyak bermain (2) masih ada anak-anak yang bingung membuat bentuk seperti apa menggunakan media magic puffer ball. \%. Hasil yang didapatkan pada siklus I masih kurang, maka peneliti melakukan penelitian 
ulang pada tahap berikutnya yaitu siklus II untuk membantu kelemahan yang masih ada pada siklus I.

\section{Siklus II}

Tahap perencanaan penelitian yang akan dilakukan pada siklus II yaitu menyusun RPPH (Rencana Program Pembelajaran Harian) dengan tema yang berbeda. Siklus II ini dilakukan sebanyak dua kali pertemuan. Siklus II pertemuan I mendapatkan hasil presentase sebanyak $61 \%$. Adanya peningkatan yang terjadi pada siklus II akan tetapi masih sama halnya belum mencapai presentase keberhasilan yaitu $75 \%$. Pada siklus ini masih membutuhkan $7 \%$ lagi untuk mencapai keberhasilan presentase yang diinginkan. Siklus II pertemuan kedua mendapatkan hasil presentase sebanyak $75 \%$, dan hasil yang didapatkan pada pertemuan kedua mencapai hasil yang diharapkan.Siklus II yang dilakukan juga sama seperti siklus I yaitu dilakukan sebanyak dua kali pertemuan. Siklus II pertemuan pertama pada saat membuat bentuk mendapatkan hasil sebesar $63 \%$ dan menambahkan assesoris sebesar $58 \%$ hasil keseluruhan yang dihitung dari keduanya yaitu $61 \%$. Siklus II pertemuan kedua pada saat membuat bentuk mendapatkan hasil sebesar $75 \%$ dan menambahkan assesoris sebesar $75 \%$ hasil keseluruhan yang didapatkan dari keduanya sebesar $75 \%$. Adanya peningkatan yang terjadi pada siklus II pertemuan kedua, sehingga kelemahan yang ada pada siklus I pertemuan pertama. Siklus I pertemuan kedua, dan siklus II pertemuan pertama dapat teratasi

\section{Perbandingan Antar Siklus}

Berikut ini adalah grafik pencapaian presentase secara keseluruhan dari prasiklus, Siklus I sampai siklus II.

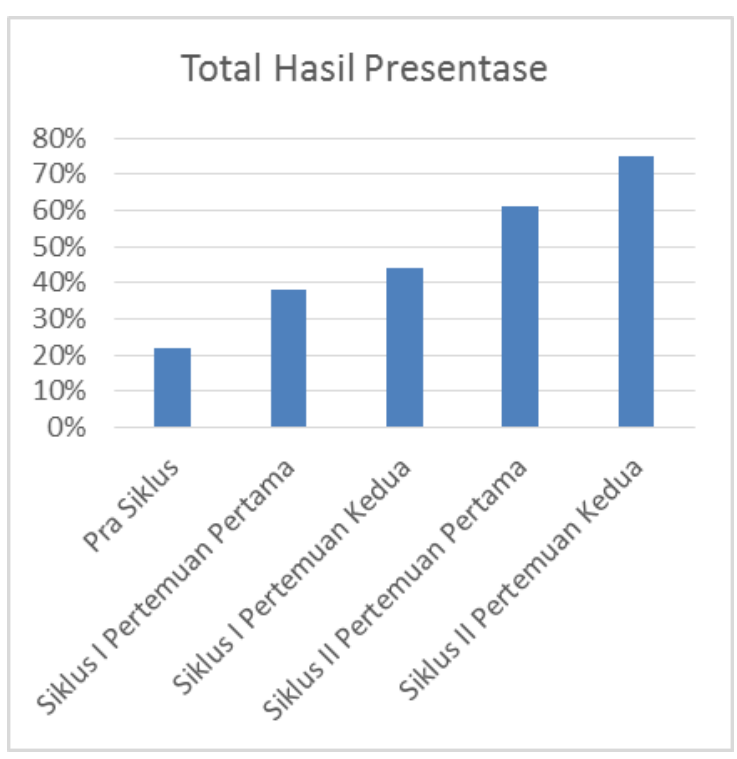

Meningkatnya kreativitas anak dapat dilihat pada grafik. Data di atas dapat disimpulkan bahwa dengan menggunakan media magic puffer ball dapat meningkatkan kreativitas anak usia 5-6 tahun. Data awal yang didapatkan pada prasiklus sebesar $22 \%$ dan belum mencapai kriteria presentase keberhasilan dan dilanjutkan pada tahap siklus I dan II hingga dapat mencapai keberhasilan yang diharapkan yaitu pada siklus II pertemun kedua mencapai $75 \%$.

\section{Pembahasan}

Dalam penelitian yang peneliti lakukan menunjukkan bahwa kreativitas anak usia dini dapat meningkat dengan menggunakan media magic puffer ball. Dengan menggunakan media magic puffer ball ini anak dapat membuat berbagai macam bentuk dan dapat dihias menggunakan asessoris yang sudah disiapkan. Pada saat membuat bentuk peneliti memberikan kesempatan kepada anak-anak untuk membuat berbagai macam bentuk sesuai dengan imajinasi, ide-ide, yang diinginkan oleh anak. Dalam hal ini sama dengan apa yang disampaikan oleh penelitian sebelumnya, yaitu belajar dengan menggunakan bermain balok unit 
dapat perpengaruh dalam meningkatkan kreativitas anak usia dini (Fauziddin, 2016).

Dalam penelitian yang dilakukan oleh peneliti, peneliti menggunakan alat atau media magic puffer ball yang dapat meningkatkan kreativitas anak. Dengan menggunakan media tersebut anak dapat membuat bentuk sesuai dengan keinginan anak, sehingga media tersebut dapat membantu untuk meningkatkan kreativitas anak. Hal ini sama dengan penelitian yang dilakukan oleh Ardiyanto menerangkan bahwa bermain dengan bentuk apapun baik itu secara aktif, pasif atau tanpa alat apapun dapat membantu meningkatkan kretivitas anak sesuai imajinatif yang dimiliki oleh anak itu sendiri (Ardiyanto, 2017)

Penelitian yang dilakukan oleh peneliti mengenai kreativitas anak. Media yang digunakan oleh peneliti adalah media magic puffer ball untuk membantu meningkatkan kreativitas anak usia dini. Didalam penelitian yang dilakukan oleh Fauziah menunjukkan data bahwa hasil penelitian yang dilakukan secara kualitatif adanya peningkatan yang terjadi mengenai kreativitas anak usia 5-6 tahun menggunakan media bahan alam. Media tersebut digunakan dalam kegiatan pembelajaran yang menarik dan bervariasi untuk anak (Fauziah, 2018)

Didalam penelitian yang peneliti lakukan mengatakan bahwa permainan yang menggunakan magic puffer ball dapat membuat suasana pembelajaran menjadi menyenangkan dan dapat memberikan ruang untuk anak dapat meningkatkan kreativitas, karena anak dapat membuat bentuk sesuai dengan keinginannya. Hal ini didukung oleh hasil penelitian yang dilakukan oleh Yosep bahwa kreativitas anak dapat meningkan dengan bantuan pembelajaran musik kreatif. Hal ini dikarenakan pembelajaran yang dilakukan menyenangkan dan memberikan kesempatan pada anak untuk mengembangkan kreativitas anak (Yosep, 2014)

Penelitian yang peneliti lakukan mendapatkan hasil bahwa dalam meningkatkan kreativitas anak dibutuhkan media. Dalam penelitian yang peneliti lakukan, peneliti menggunakan media magic puffer ball untuk meningkatkan kreativitas anak usia dini. Hal ini sama dengan penelitian yang dilakukan oleh Miranda bahwa dalam penelitiannya menggunakan buku cerita berbasis karakter untuk meningkatkan kreativitas anak. Dengan menggunakan media anak dapat meningkatkan kreativitasnya (Miranda, 2018)

\section{KESIMPULAN}

Berdasarkan hasil penelitian yang telah dilakukan dapat disimpulkan bahwa kreativitas membantu anak untuk menemukan ide-ide, berimajinasi untuk membuat sesuatu hal yang baru. Untuk itu pemberian rangsangan kreativitas kepada harus diberikan pada anak semenjak anak masih berusia dini. Melalui penggunaan media magic puffer ball dapat memberikan pengaruh pada anak mengenai kreativitas yang terjadi pada hasil prasiklus sampai siklus II mengalami peningkatan. Media magic puffer ballI dapat digunakan sebagai sarana prasarana disekolah TK Marsudirini Sang Timur Salatiga.

\section{UCAPAN TERIMAKASIH}

Peneliti mengucapkan terima kasih kepada pihak sekolah yang telah memberikan waktu dan kesempatan kepada peneliti untuk melakukan penelitian.

\section{DAFTAR PUSTAKA}

Ardiyanto, A. (2017). Bermain Sebagai Sarana Pengembangan Kreativitas Anak Usia Dini. Jendela Olahraga. https://doi.org/10.26877/jo.v2i2.1700 
Djuniartiningsih. (2012). Meningkatkan Kreativitas Anak K Lompok B Di Tk “ Merpati Pos " Surabaya Universitas Negeri Surabaya. Jurnal UNESA.

Fakhriyani, D. V. (2018). Pengembangan Kreativitas Anak Usia Dini. Wacana Didaktika, 4(2), 193-200. https://doi.org/10.31102/wacanadidaktika .4.2.193-200

Fauziah, N. (2018). Penggunaan Media Bahan Alam Untuk Meningkatkan Kreativitas Anak. JIV, 8(1), 23-30. https://doi.org/10.21009/jiv.0801.4

Fauziddin, M. (2016). Penerapan Belajar Melalui Bermain Balok Unit untuk Meningkatkan Kreativitas Anak Usia Dini. Jurnal Curricula, 1(3), 1-11. https://doi.org/http://dx.doi.org/10.22216/ JCC.2016.v2i3.1277

Husna Handayani, P. (2018). Pengembangan Kreativitas Anak Usia Dini Dalam Keluarga. Jurnal Keluarga Sehat Sejahtera. https://doi.org/10.24114/jkss.v15i2.8774

Istiqomah, D. (2017). Kreativitas dan Pengembangannya dalam Perspektif Teori Ernst Kris. Golden Age: Jurnal Ilmiah Tumbuh Kembang Anak Usia Dini.

Kartini, K., \& Sujarwo, S. (2017). Penggunaan Media Pembelajaran Plastisin Untuk Meningkatkan Kreativitas Anak Usia. Jurnal Pendidikan Dan Pemberdayaan Masyarakat, $\quad 1(2), \quad 199$. https://doi.org/10.21831/jppm.v1i2.2689

MAHNUN, N. (2012). pengertian media pembelajaran. Jurnal Pemikiran Islam.

Miranda, D. B. C. B. P. K. (2018). Akter Untuk Meningkatkan Kreativitas Aud. Jurnal Visi Ilmu Pendidikan, 10(1), 18. https://doi.org/10.26418/jvip.v10i1.2597 5

Munfarijah, S. (2018). Upaya Meningkatkan Motivasi Kerja Dan Kreativitas Dalam Kepemimpinan Paud. Jurnal Kependidikan, 3(2), 163-182. https://doi.org/10.24090/jk.v3i2.905

Nirwana, N., Widyaningsih, O., \& Sapaile, N. (2019). Pelatihan Kreativitas Clay Bagi Guru Paud Kecamatan Tambora, Jakarta Pusat. Sarwahita, 15(01), 13-21. https://doi.org/10.21009/sarwahita.151.0
2

Priyanto, A. (2014). Pengembangan Kreativitas Pada Anak Usia Dini Melalui Aktivitas Bermain. Pengembangan Kreativitas Pada Anak Usia Dini Melalui Aktivitas Bermain.

Sari, L. P. P., Antara, P. A., \& Ujianti, P. R. (2017). Pengaruh Strategi Permainan Imajinatif terhadap Kreativitas Anak Kelompok B Gugus III Kecamatan Buleleng. Journal Pendidikan Anak Usia Dini.

Yosep, W. (2014). Pembelajaran Musik Kreatif Pada Anak Usia Dini (The Learning of Creative Music in Early-childhood Children). Harmonia: Journal of Arts Research and Education, 5(1), 190-200. https://doi.org/10.15294/HARMONIA.V $5 \mathrm{I} 1.829$ 